\title{
Diagnosis and Acute Management of Spinal Cord Injury: Current Best Practices and Emerging Therapies
}

\author{
Allan R. Martin ${ }^{1}$ - Izabela Aleksanderek ${ }^{2}$ - Michael G. Fehlings ${ }^{1}$
}

Published online: 24 June 2015

(C) Springer International Publishing AG 2015

\begin{abstract}
The diagnosis and management of spinal cord injury (SCI) have continuously evolved over decades of clinical experience. We now understand that the injured spinal cord is in a precarious state, experiencing a complex cascade of inflammatory events and hemodynamic compromise. Careful navigation is required at each stage, from emergency personnel to the spinal surgeon who reconstructs the damaged spine, to minimize secondary injury and optimize neurological outcome. Future advances in SCI diagnosis will likely utilize novel MRI techniques that characterize spinal cord microstructure and functional connectivity. The acute management of SCI is likely to undergo a radical transformation, with numerous potential treatments used in combination, such as neuroprotective and regenerative pharmaceuticals, cellular transplantation, and implantation of structural scaffolds. In this review, we summarize current best practices in diagnosis and acute management of SCI, highlight areas of controversy, and introduce emerging therapies that are candidates for translation to clinical use.
\end{abstract}

This article is part of the Topical Collection on Blunt Spinal Trauma

Allan R. Martin

allan.martin@utoronto.ca

1 Division of Neurosurgery, University of Toronto, 399 Bathurst St., Toronto, Ontario M5T 2S8, Canada

2 Division of Genetics \& Development, Toronto Western Hospital, 399 Bathurst St., Toronto, Ontario M5T 2S8, Canada
Keywords Spinal cord injury · Diagnosis · Acute management $\cdot$ Emerging therapies $\cdot$ Current best practices . Surgical decompression $\cdot$ Riluzole $\cdot$ Neuroprotective strategies · Induced hypothermia $\cdot$ Methylprednisolone . Cethrin · Minocycline · G-CSF · Chondroitinase · Regenerative pharmaceuticals $\cdot$ Cellular transplantation . Functional rehabilitation

\section{Introduction}

\section{Pathophysiology of Spinal Cord Injury}

The biological processes in traumatic spinal cord injury (SCI) can be divided into primary and secondary injury, followed by regeneration and functional recovery. Primary injury describes the immediate cellular and extra-cellular damage incurred by destructive forces and energy transfer. Secondary injury involves a cascade of mechanisms beginning immediately and lasting for weeks, including ischemia, vasospasm, thrombosis, inflammatory cytokines, breakdown of the blood-brain barrier, ion-mediated cellular damage, glutamate-related excitotoxicity, oxidative cellular damage, peroxidation of membrane lipids, sodium- and calcium-mediated cell injury, and apoptosis (Fig. 1) [1]. Secondary injury can be exacerbated by extrinsic factors such as spinal instability causing repetitive trauma and systemic hypoxia, hypotension, and metabolic derangements that further injure the compromised tissue. The cord then undergoes a period of regeneration, involving cellular signaling, axonal regrowth, remyelination, and reconnection of synapses. These complex biological processes present a host of potential targets for pharmaceutical and cell-based therapies. 


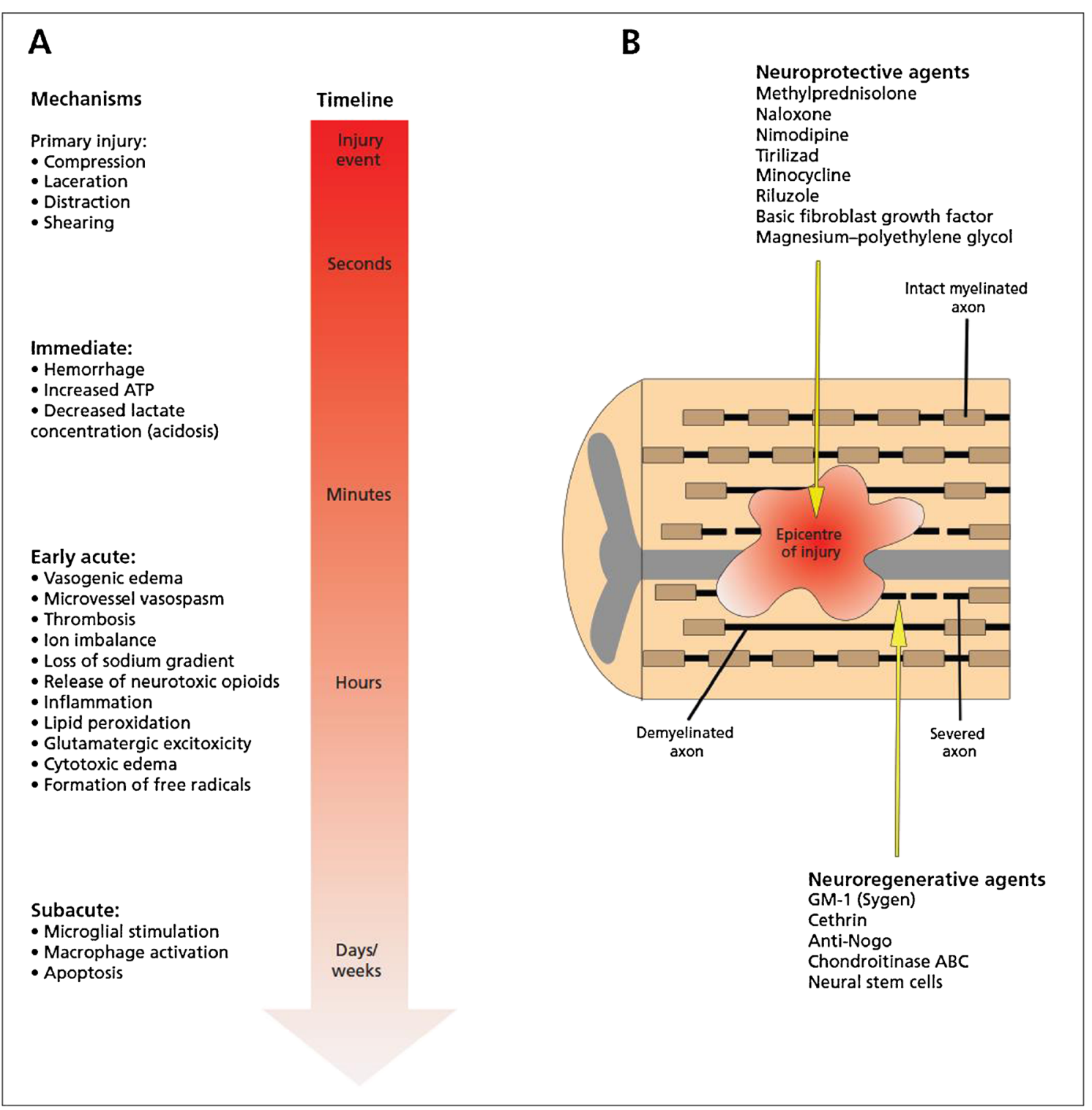

Fig. 1 a Primary and secondary mechanism of injury determining the final extent of spinal cord damage. The primary injury event starts a pathobiological cascade of secondary injury mechanism that unfolds in different phases within seconds of the primary trauma and continuing for several weeks thereafter. b longitudinal section of the spinal cord after injury. The epicentre of the injury progressively expands after the primary trauma as a consequence of secondary injury events. This expansion causes an increased region of tissue cavitation and, ultimately, worsened long-term outcomes. Within and adjacent to the injury epicentre are severed and demyelinated axons. The neuroprotective agents listed act to subvert specific secondary injuries and prevent

\section{Clinical Presentation and Diagnosis}

The mechanism involved in traumatic SCI often determines the injury pattern, severity of neurological impairment, and potential for recovery. The remaining spinal cord tissue bridges are precarious, and meticulous care must be taken to minimize secondary injury mechanisms. As a result, it is ideal that these patients are efficiently neural damage, while the neuroregenerative agents act to promote axonal regrowth once damage has occurred. ATP adenosine triphosphate. Reprinted from Wilson JR, Forgione N, Fehlings MG. Emerging therapies for acute traumatic spinal cord injury. Figure 1. Canadian Medical Association Journal April 2, 2013, 185(6):485-492. (C) Canadian Medical Association (2013). This work is protected by copyright and the making of this copy was with the permission of the Canadian Medical Association Journal (www.cmaj.ca) and Access Copyright. Any alteration of its content or further copying in any form whatsoever is strictly prohibited unless otherwise permitted by law

transferred to tertiary care centers with highly specialized teams (Table 1) $[2 \bullet \bullet]$.

\section{First Responders}

The clinical presentation of traumatic SCI typically involves the activation of emergency medical services (EMS), who must assess and manage trauma victims on scene. This pre- 
Table 1 Current best practices for the diagnosis and management of SCI. Listed are several key recommendations, many of which are from the 2013 updated guidelines from the Joint Section on Disorders of the
Spine and Peripheral Nerves of the American Association of Neurological Surgeons and the Congress of Neurological Surgeons [2••]

\begin{tabular}{|c|c|c|}
\hline Topic & $\begin{array}{l}\text { Level of AANS/CNS } \\
\text { recommendation }\end{array}$ & Guideline/recommendation \\
\hline \multirow[t]{2}{*}{ Hypotension } & Level III & Correction of hypotension to systolic blood pressure $>90 \mathrm{mmHg}$ as soon as possible \\
\hline & Level III & Maintenance of mean arterial blood pressure between 85 and $90 \mathrm{mmHg}$ for 7 days \\
\hline Hypoxia & None & Hypoxia $\left(\mathrm{PaO}_{2}<60 \mathrm{mmHg}\right.$ or $\mathrm{O}_{2}$ saturation $\left.<90 \%\right)$ should be avoided [3] \\
\hline ICU monitoring & Level III & $\begin{array}{l}\text { SCI patients should be managed in an ICU setting with cardiac, hemodynamic, and } \\
\text { respiratory monitoring to detect cardiovascular dysfunction and respiratory insufficiency }\end{array}$ \\
\hline \multirow[t]{2}{*}{ Immobilization } & Level II & Patients with SCI or suspected SCI (except in penetrating injury) should be immobilized \\
\hline & Level III & $\begin{array}{l}\text { Spinal immobilization should be performed with rigid cervical collar and supportive blocks } \\
\text { on a backboard with straps }\end{array}$ \\
\hline Specialized centers & Level III & SCI patients should be transferred expediently to specialized centers of SCI care \\
\hline Examination & Level II & The ASIA ISNCSCI examination should be performed and documented \\
\hline \multirow[t]{3}{*}{ Imaging } & Level I & $\begin{array}{l}\text { No cervical imaging is required in awake trauma patients that have no neck pain/tenderness, } \\
\text { normal neurological examination, normal range of motion, and no distracting injuries }\end{array}$ \\
\hline & Level I & $\mathrm{CT}$ is recommended in favor of cervical X-rays \\
\hline & Level I & CT angiography is recommended in patients who meet the modified Denver screening criteria [4] \\
\hline Neuroprotection & Level I & Methylprednisolone is not recommended ${ }^{\mathrm{a}}$ \\
\hline \multirow[t]{2}{*}{ Spinal cord decompression } & None & $\begin{array}{l}\text { Surgical decompression prior to } 24 \mathrm{~h} \text { after SCI can be performed safely and is associated } \\
\text { with improved neurological outcome [5•• }]\end{array}$ \\
\hline & Level III & $\begin{array}{l}\text { Early closed reduction of fracture/dislocation in awake patients without a rostral injury } \\
\text { is recommended, and pre-reduction MRI does not appear to influence outcome }\end{array}$ \\
\hline
\end{tabular}

${ }^{\mathrm{a}}$ The authors do not agree with this guideline

hospital care uses protocols such as advanced trauma life support (ATLS) that focus on securing airway, breathing, and circulation before performing a full assessment of injuries. Periods of hypotension below $90 \mathrm{mmHg}$ are associated with worse neurological outcomes in SCI [2••], and evidence extrapolated from traumatic brain injury (TBI) suggests that hypoxia is also deleterious [3]. With suspected SCI, movements of the patient or extrication from motor vehicle collisions must be carefully performed and the spine should be immobilized with a hard collar and supportive blocks on a backboard with straps [2••]. Similarly, on-scene intubation may be needed, where careful in-line stabilization of the cervical spine is mandatory.

\section{Trauma Teams}

Emergency hospital personnel have the difficult role of stabilizing critically ill patients while assessing for injuries to multiple systems. One of the major hurdles in polytrauma SCI patients is managing shock, which may include both hypovolemic and neurogenic causes due to loss of sympathetic tone. This is treated with crystalloid fluid, blood products, and intravenous vasopressors such as norepinephrine or phenylephrine (phenylephrine is the first-line pressor of choice for neurogenic shock) that provide alpha-adrenergic vascular tone $[2 \cdot \bullet]$.

Ideally, the trauma team includes a spine surgeon that can participate in the initial assessment, including neurological and spine examinations. The neurological exam is often abbreviated to get an overall impression of motor and sensory impairments without stalling urgent procedures or imaging. However, an American Spinal Injury Association (ASIA) International Standards for Neurological Classification of SCI (ISNCSCI) examination should be performed once the patient is fully resuscitated and stable $[2 \bullet \bullet]$. The motor exam may reveal "spinal shock", a term that describes flaccid paralysis below a specific spinal level (not to be confused with "neurogenic shock" - a cardiovascular phenomenon of severely decreased peripheral resistance). Spinal shock is most commonly associated with severe SCI (ASIA Impairment Scale (AIS) A or B). The patient should be carefully logrolled to remove the backboard, which quickly causes pressure ulcers in denervated skin, and the spine inspected and palpated at every level from $\mathrm{C} 1$ to the sacrum to identify bruising, tenderness, bogginess, steps, and gaps, which can indicate fractures or ligamentous injuries. Rectal examination assesses for tone, bulbocavernous reflex, and sensation (light touch and pinprick at the mucocutaneous junction and deep pressure sensation), and voluntary contraction [6]. 


\section{Spine Imaging}

Although SCI largely remains a clinical diagnosis, imaging is essential to confirm and localize the level of injury. Cervical spine X-rays, including AP, lateral, and open mouth views, can identify most cervical fractures but miss approximately $6 \%$ [7]. CT is the preferred modality, and guidelines recommend its use in all obtunded patients or awake patients with neck pain or neurological deficit. CT of the T/L spines should also be performed in high-energy mechanisms or when cervical fractures are present [8]. A detailed categorization of spinal injuries is beyond the scope of this manuscript but can be found from numerous sources $[9,10]$. CT angiography to rule out carotid/vertebral dissection should be considered, according to the modified Denver screening criteria for blunt cerebrovascular injury [4].

The role of MRI in acute trauma remains unclear, but guidelines recommend MRI within $48 \mathrm{~h}$ in obtunded patients to rule out cervical injury and allow collar removal $[2 \bullet \bullet$. MRI is also beneficial in awake patients with pain or neurological deficits to assess for ligamentous injury, epidural or intramedullary hematoma, and disc herniation. The authors suggest that patients with unexplained neurological deficits should have an MRI study performed urgently since CT is inadequate to assess for ongoing cord compression and timely surgical decompression improves outcomes [5••].
Unfortunately, MRI remains a constrained resource, which has prevented widespread uptake in trauma protocols and guidelines.

Conventional MRI (T1-, T2-, and proton density-weighted) images give a macrostructural view of the spine but do not characterize the cord tissue and thus cannot provide reliable prognostic information. However, emerging MRI techniques can overcome these limitations. Diffusion tensor imaging measures directional water diffusivity and can quantify its integrity $[11 \bullet, 12 \bullet$. Magnetization transfer provides a surrogate measure of myelin quantity $[11 \bullet, 12 \bullet]$. Functional MRI can interrogate the activity and connectivity of spinal circuits, evaluating the extent of injury and subsequent neuroplasticity $[11 \cdot, 13 \bullet]$. Early studies of these methods suggest that they may be able to differentiate between reversible and irreversible components of cord injury, ultimately providing longterm prognosis and guiding targeted therapies (e.g., remyelination) to optimize recovery $[12 \bullet]$.

\section{Acute Management of SCI}

Once the diagnosis of SCI is made, the primary goal of management is avoidance of secondary injury (Fig. 1). A proposed algorithm for optimal care is presented in Fig. 2. Expedient transfer to an intensive care unit (ICU) with respiratory,

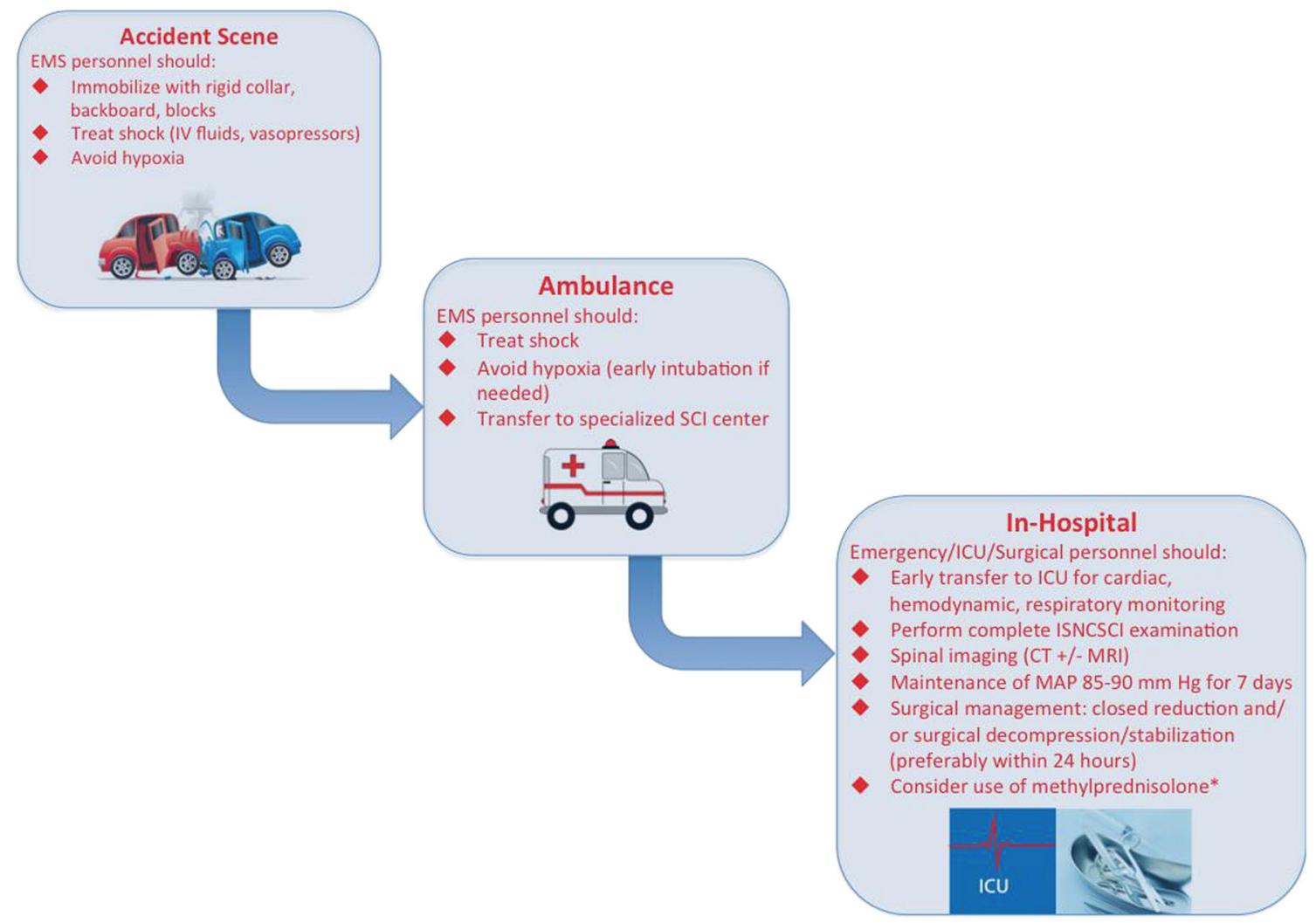

Fig. 2 Proposed algorithm for optimal SCI care from scene to ICU. Asterisk the use of methylprednisolone is not recommended in the 2013 AANS/CNS $\mathrm{SCI}$ guidelines 
cardiac, and hemodynamic monitoring is critical as it has been shown to improve morbidity, mortality, and neurological outcomes [14]. Levi et al. established in 1993 that hypotension due to neurogenic shock is common in SCI patients (primarily in cervical, motor-complete injuries), and prompt and aggressive treatment appeared to improve mortality and neurological outcomes [15]. A subsequent observational study of $77 \mathrm{SCI}$ patients by Vale et al. suggested that maintaining a mean arterial pressure (MAP) $>85 \mathrm{mmHg}$ with crystalloids and/or vasopressors for 7 days following injury showed markedly improve neurological outcomes compared with historical controls [16], leading to the guideline of maintaining MAP 85$90 \mathrm{mmHg}$ for 7 days [2••]. However, this strategy requires lengthy ICU monitoring, prompting a current clinical trial to explore lower targets [17]. Beyond these supportive measures, acute treatment involves spinal cord decompression, spinal stabilization, neuroprotective strategies, and regenerative therapies. A summary of key recommendations for management best practices is listed in Table 1 .

\section{Spinal Cord Decompression}

The spinal cord frequently faces ongoing mechanical compression (causing focal ischemia) following SCI, in which case a decompressive procedure should be performed as quickly as possible $[18 \bullet, 19 \bullet]$. This is well supported in animal models of SCI [20], but concerns of hemodynamic instability and insufficient evidence left this as an area of controversy until recently. The prospective non-randomized Surgical Timing in Acute Spinal Cord Injury Study (STASCIS) involved 313 cervical SCI patients and demonstrated that patients receiving surgery within the first $24 \mathrm{~h}$ (mean $14.2 \mathrm{~h}$ ) were 2.8 times more likely to see a 2 -grade AIS improvement compared with after $24 \mathrm{~h}$ (mean $48.3 \mathrm{~h}$ ) [5••]. This study also confirmed that early surgery is safe, with no difference in complication rates (early $24 \%$ vs. late $30 \%, p=0.21$ ). Two recent observational studies in large Canadian cohorts also demonstrated significant benefits of early surgery, although it was observed in one of these studies that the benefit was not found in AIS A patients [18•, 19•]. With a design similar to STASCIS, a European multi-center study entitled SCI-POEM is currently underway [21]. In light of the current evidence, the authors suggest that surgical decompression in acute SCI should be performed as quickly as operating room resources allow.

In fracture-dislocations of the spinal column, an additional decompression option is closed reduction with cervical traction. Evidence suggests that closed reduction is safe in awake patients without an additional rostral injury and effective in $80 \%$ of cases [22]. However, the fear of disc herniation prevents many surgeons from performing a closed reduction without a pre-reduction MRI [23]. These studies show herniated intervertebral discs in up to $55 \%$ of cases, whereas the rate of permanent neurological deterioration following closed reduction is $1 \%$, although specific causes were not reported [22-24]. Although the current AANS/CNS Guidelines suggest that the utility of pre-reduction MRI in awake patients is uncertain, the authors suggest that closed reduction without pre-reduction MRI is the rational approach for these cases, given the impetus to decompress the spinal cord quickly and the potential for additional injury during transfers with an unstable C-spine.

\section{Spinal Stabilization}

The optimal method of spinal stabilization may include anterior and/or posterior surgical approaches, halo-vest, external bracing, or rigid collar, depending on the pattern of bony and ligamentous injury. Decisions regarding spinal stabilization are complex and relate to the injury morphology (fracture pattern and injury mechanism), degree of ligamentous injury, and neurological status (with incomplete injuries usually prompting more aggressive treatment than complete). Specific approaches are described elsewhere, but the authors endorse consultation with a senior spine surgeon for difficult cases to optimize decision-making.

\section{Neuroprotective Strategies}

The concept of neuroprotection dates back to ancient Greece, where physicians treated cranial injuries by inducing hypothermia with ice baths [25]. Efforts have been made to develop neuroprotective drug treatments for many neurological conditions, and substantial overlap exists in their underlying mechanisms of action such that specific agents may have potential to treat multiple diseases. However, further work is needed to develop highly effective neuroprotective agents and establish their efficacy. The optimal timing of neuroprotective therapies is generally as soon as possible, but this poses a challenge for clinical trials that require the diagnosis and consent processes to occur before a treatment is provided. The emerging array of potential acute-phase therapies includes pharmaceuticals, cell transplants, and structural scaffolds (Table 2).

\section{Induced Hypothermia}

Hypothermia instantly became a hot topic in 2007 when a professional football player sustained a severe cervical SCI (reports are unclear whether it was AIS B or C) and was treated with systemic hypothermia, recovering to AIS D and walking just months later. Kwon et al. provided commentary on this event in a subsequent review of therapeutic hypothermia: "It remains speculative as to the extent to which his neurological recovery is attributable to systemic hypothermia as opposed to the effects of early decompression or even the 
Table 2 Potential therapeutic agents (pharmacological, cell-based, or implanted materials). Following is a summary of the most promising neuroprotective and therapeutic agents in which clinical studies have been completed or are under current study

\begin{tabular}{|c|c|c|c|c|}
\hline Class & Type & Agent & Description & Completed/ongoing studies \\
\hline \multirow[t]{6}{*}{ Neuroprotective } & Temperature & Hypothermia & $\begin{array}{l}\text { The induction of moderate hypothermia (33C) } \\
\text { through intravascular or extrinsic cooling }\end{array}$ & $\begin{array}{l}\text { Case-control study of } 14 \text { AIS A patients, } \\
\text { trend toward neurological improvement } \\
(43 \% \text { vs. } 21 \%)[26]\end{array}$ \\
\hline & \multirow[t]{5}{*}{ Pharmaceutical } & $\begin{array}{l}\text { Methyl- } \\
\text { prednisolone }\end{array}$ & $\begin{array}{l}\text { Potent corticosteroid that inhibits inflammation, } \\
\text { administered intravenously (IV) }\end{array}$ & $\begin{array}{l}\text { Subgroup analysis shows modest (4-point) } \\
\text { motor improvement with } 24 \text {-hour MP } \\
\text { initiated within } 8 \text { hours }[27 \cdot \bullet]\end{array}$ \\
\hline & & Riluzole & $\begin{array}{l}\text { Voltage-gated sodium channel blocker, } \\
\text { mitigates glutamatergic toxicity, } \\
\text { administered orally }\end{array}$ & $\begin{array}{l}\text { Riluzole-treated cervical subgroup }(n=28) \\
\text { improved } 15.5 \text { points }{ }^{\mathrm{a}} \text { more than matched } \\
\text { controls }(p=0.02), \text { no benefit in thoracic } \\
(n=8)[28 \cdot] \text {; phase II/III RISCIS trial } \\
\text { underway [29] }\end{array}$ \\
\hline & & Minocycline & $\begin{array}{l}\text { Tetracycline anti-inflammatory, reduces } \\
\text { microglial activation, TNF-alpha, inhibits } \\
\text { NOS and metalloproteinases, administered IV }\end{array}$ & $\begin{array}{l}\text { Minocycline-treated cervical subgroup }(n=25) \\
\text { improved } 14 \text { points }^{\mathrm{a}} \text { compared with placebo } \\
(p=0.05)\left[30^{\bullet}\right] \text {; phase III MASC trial } \\
\text { underway [31] }\end{array}$ \\
\hline & & G-CSF & $\begin{array}{l}\text { Endogenous glycoprotein attracts stem cells, } \\
\text { preserves myelin, suppresses TNF-alpha } \\
\text { and IL-1, and promotes angiogenesis, } \\
\text { administered IV }\end{array}$ & $\begin{array}{l}\text { Two early phase studies with IV injection } \\
\text { showed safety and AIS grade improvements } \\
\text { in } 16 / 16(100 \%) \text { and } 15 / 17(88 \%) \text { of pa- } \\
\text { tients, respectively }[32 \cdot, 33 \bullet]\end{array}$ \\
\hline & & FGFs & $\begin{array}{l}\text { Signals glia to forms "glial bridge" over which } \\
\text { regenerating axons can traverse, reduces } \\
\text { glutamate-related excitotoxicity, administered } \\
\text { IV }\end{array}$ & $\begin{array}{l}\text { Recombinant basic FGF (SUN13837) } \\
\text { engineered to avoid stimulating fibroblast } \\
\text { proliferation is subject of phase II RCT [34] }\end{array}$ \\
\hline
\end{tabular}

Mg; PEG Magnesium: glutamate NMDA receptor

Regenerative Pharmaceutical Cethrin

NSAIDs

Anti-Nogo-A antibodies

Chondroitinase Degrades sugar chains and chondroitin sulphate $\mathrm{ABC}$

Hepatocyte growth factor

Cell-based Bone marrow stromal cells (BMSCs)

Adult neural stem cells

Adiposederived stem cells

Schwann cells

Human embryonic stem cells antagonist, anti-inflammatory; PEG: helps $\mathrm{Mg}$ cross $\mathrm{BBB}$, preserves axonal membranes, administered IV

Inactivates rho or its downstream target ROK in order to stimulate neurite growth, administered intraoperatively (extradural)

Inhibitory properties on the Rho pathway, prompting increased axonal sprouting, administered orally

The myelin protein Nogo-A is a potent inhibitor of neurite growth, administered intrathecally (via pump) proteoglycans within glial scar, promotes axonal regrowth, administered intraspinally

Proprietary formation of $\mathrm{Mg} / \mathrm{PEG}$ (AC105) now under investigation in multi-center phase II trial [35]

Cethrin-treated cervical patients improved 18.6 $(+/-19.3)$ points $^{\mathrm{a}}$ (trend over historic controls) [36•]; phase III trial is planned [37]

Phase I trial of ibuprofen currently underway [38]

Phase I trial of anti-Nogo-A antibody (ATI355) completed, results pending publication [39]

Design of human formulation underway, phase I trial anticipated

Neurotrophic factor and promotes angiogenesis, administered intraspinally

Phase I/II study of recombinant human HGF (KP-100IT) currently underway [40]

Marrow cells include stem cells and other cells at varying maturation, spun to yield only mononuclear cells; mechanism is both cell signalling and repopulation of injured cells, administered intraspinally

Allogeneic cells extracted from CNS of healthy donors (possibly from the subventricular zone)

Cells extracted and incubated, unclear if reprogrammed to pluripotency, administered intraspinally

Autologous cells obtained from sural nerve, administered intraspinally

Cells derived from human embryos, cultured and injected intraspinally
Phase II trial of intraspinal cells and GM-CSF intravenously in 35 AIS A patients, nonsignificant improvement over controls [41]; a separate study of BMSCs injected intraspinally in thoracic AIS A patients is ongoing [42]

A proprietary product is the subject of an ongoing phase II study [43]

A phase II study inserting cells intraoperatively is underway [44]

Phase I trial of 33 chronic thoracic SCI patients showed safety but no improvement [45]

Study by Geron Corp (Menlo Park, CA) stopped before completion after four patients received intraspinal injections 
Table 2 (continued)

\begin{tabular}{|c|c|c|c|c|}
\hline Class & Type & Agent & Description & Completed/ongoing studies \\
\hline & Tissue-based & $\begin{array}{l}\text { Bioengineered } \\
\text { scaffolds } \\
\text { and tissue } \\
\text { grafts }\end{array}$ & $\begin{array}{l}\text { Synthetic and/or biological tissues providing } \\
\text { structural construct are implanted/injected to } \\
\text { bridge the injury and permit axonal regrowth, } \\
\text { administered intraspinally }\end{array}$ & No human studies to date \\
\hline
\end{tabular}

GM-CSF granulocyte macrophage-colony stimulating factor

${ }^{\mathrm{a}}$ Points refer to AISA Motor Score points

high rates of spontaneous recovery, which are seen in cases of severe, but incomplete SCI [46].” This attention also spawned numerous animal studies that demonstrated intravascular cooling to moderate hypothermia $\left(32-34{ }^{\circ} \mathrm{C}\right)$ attenuates secondary injury [47]. Decades ago, intraoperative direct cooling of the spinal cord was common, but studies failed to show a clear benefit [48•]. One clinical trial of systemic hypothermia in acute SCI has been completed: a retrospective case-control study of 14 AIS A patients showing similar complication rates and a trend toward neurological improvement (43 vs. $21 \%$ ) [26]. Further evidence is needed before hypothermia is adopted widely, prompting a phase II prospective nonrandomized study that is currently underway [49].

\section{Methylprednisolone}

Methylprednisolone (MP) is a potent corticosteroid that inhibits inflammation and membrane lipid peroxidation, previously used widely in SCI. However, much debate and controversy has followed MP, including the recent reversal of the AANS/CNS guidelines from "treatment option" to "treatment not recommended" in spite of minimal change in available evidence and no discussion of the recent Cochrane review that

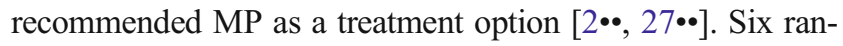
domized controlled trials (RCTs) and numerous observational studies were thoroughly analyzed in this Cochrane metaanalysis $[27 \bullet \bullet]$. Unfortunately, the meta-analysis provided mixed results: overall, MP showed no neurological benefit, but subgroup analysis demonstrated a 4-point improvement on ASIA motor score with 24-h MP administration initiated within $8 \mathrm{~h}$. The data also showed doubling of wound infection and gastrointestinal bleeding rates, but conversely a trend toward decreased mortality. The Cochrane review concludes that MP appears to be effective, but critics contend that the evidence regarding complications is clear, whereas the efficacy analysis is methodologically flawed [2••]. Of interest, cervical data from STASCIS demonstrated a $44 \%$ reduction in complication rates with MP administration, possibly because cervical wound infections are less common than at caudal levels [5••]. Furthermore, cervical SCIs have greater potential for recovery than thoracic or lumbar injuries, suggesting that future studies may be better powered by focusing solely on the cervical population [50]. Based upon the available evidence from the Cochrane review (the highest level of the evidentiary pyramid) and STASCIS, it appears that MP offers a small neurological benefit (with the aforementioned additional risks) and may have a role in otherwise healthy patients with cervical injuries treated within $8 \mathrm{~h}$ [50]. However, this issue remains a subject of intense debate among SCI clinicians; the newer AANS/CNS guidelines have not been widely accepted by the SCI community, and recommendations for the use of MP are currently under review by other SCI groups.

\section{Riluzole}

Riluzole is a benzothiazole molecule that blocks voltage-gated sodium channels and mitigates glutamatergic toxicity and astrocytosis [51]. This drug received regulatory approval in the 1990s for treatment of amyotrophic lateral sclerosis (ALS), in which it slows degeneration of motor neurons and prolongs survival [52]. In animal models, riluzole attenuates secondary injury and improves behavioral outcomes [51]. Recently, a phase I/II clinical study has been completed in 36 AIS A-C patients ( 28 cervical and 8 thoracic), and riluzole-treated cervical patients improved 15.5 points more than matched controls from a registry $(p=0.02)$ [28•]. The findings have justified a multi-center phase II/III RCT entitled Riluzole in SCI Study (RISCIS) that is now underway in cervical SCI [29].

\section{Minocycline}

Minocycline is a lipid-soluble tetracycline derivative with antibiotic and anti-inflammatory properties, used for treating acne with established safety. Its mechanism is multifaceted, including reducing microglial activation and TNF-alpha, while inhibiting nitric oxide synthase (NOS) and metalloproteinases $[53,54]$. Pre-clinical studies show that minocycline has a neuroprotective effect after SCI, improving motor function, reducing lesion size, and preserving axons [53, 54]. A singlecenter RCT of minocycline versus placebo was completed, showing one event of transient hepatic enzyme elevation and a weak trend toward improvement on ASIA motor scores (6 points, $n=44, p=0.20$ ), with the cervical subgroup 
demonstrating substantially more improvement ( 14 points, $n=$ $25, p=0.05)\left[30^{\bullet}\right]$. These encouraging results have prompted the Minocycline in Acute Spinal Cord Injury (MASC) multicenter phase III trial, which is ongoing for cervical injuries [31].

\section{Granulocyte Colony-Stimulating Factor}

Granulocyte colony-stimulating factor (G-CSF) is an endogenous glycoprotein known for its hematopoietic functions, including mobilization of bone marrow-derived stem cells to the blood. Animal studies have reported numerous nonhematopoietic functions of G-CSF, including neuroprotective effects in SCI and stroke by preserving myelin, suppressing TNF-alpha and IL-1, promoting angiogenesis, and attracting stem cells to the injury site [55]. A phase I/IIa trial of intravenous injection in 16 humans demonstrated safety and impressive efficacy, with all 16 patients showing improvement in AIS grade [32•]. A subsequent multi-center non-randomized controlled study also showed intriguing results, with 15 of 17 subjects receiving G-CSF improving at least one AIS grade [33•].

\section{Fibroblast Growth Factors}

Several forms of fibroblast growth factor (FGF) have been investigated after the discovery that zebrafish, which can regenerate their spinal cord following transection, use FGF signalling to form a "glial bridge" over which regenerating axons can traverse [56]. The exact mechanisms of FGF remain elusive and vary between acidic and basic FGF but include the neuroprotective effect of reducing glutamate-related excitotoxicity and enhancing axonal regrowth [56]. Preclinical studies show that intravenous or intrathecal administration of bFGF dramatically improves hind limb function in SCI rat models [57]. A recombinant analog of bFGF (SUN13837) engineered to avoid stimulating fibroblast proliferation is the subject of a current multi-center phase II placebo-controlled RCT [34].

\section{Inhibitors of Glutamate-Related Excitotoxicity}

Several other potential therapies also involve counteracting glutamate-related excitotoxicity. GM-1 gangioside (Sygen) is a membrane protein that reduces glutamatergic excitotoxicity and apoptosis and enhances neuritic sprouting [58]. However, a multi-center RCT enrolling 797 patients within $72 \mathrm{~h}$ of injury failed to show improvement at 1 year [58], resulting in "treatment not recommended" by the AANS/CNS guidelines [2••]. Magnesium $(\mathrm{Mg})$ is an established neuroprotective agent used in a host of neurological disorders, with theorized neuroprotective mechanisms of non-competitive antagonism of glutamate NMDA receptors, reduction of free radicals, and inhibition of inflammatory cytokines [59]. In animal studies, a formulation of $\mathrm{Mg}$ chloride in polyethylene glycol (PEG) to allow greater penetration of the blood-brain barrier facilitated better locomotor recovery than MP [60]. Furthermore, PEG itself has substantial neuroprotective properties, preserving or resealing axonal membranes and reducing oxidative stress [61]. A proprietary formation of $\mathrm{Mg} / \mathrm{PEG}$ dubbed $\mathrm{AC} 105$ is now under investigation in a multi-center phase II trial [35].

\section{Other Pharmacological Agents}

The pre-clinical field of SCI research is vast, and myriad other agents have been scrutinized for neuroprotective properties. Erythropoietin has non-hematopoietic effects that inhibit apoptosis and inflammation and enhance angiogenesis [62]. Recombinant techniques have produced erythropoietin derivatives that avoid stimulating erythropoiesis but have yet to be tested in humans [62]. Rolipram is a phosphodiesterase 4 inhibitor with anti-inflammatory properties, shown to improve functional outcomes in rat SCI [63].

Of historical interest, three additional agents have been studied in human trials. Naloxone, an opiate receptor antagonist that reduces NOS and superoxide dismutase activity, failed to show any benefit compared with placebo in NASC IS II [64]. Tirilazad, a synthetic 21-aminosteroid specifically designed to inhibit peroxidation of membrane lipids, showed equivalent efficacy to MP in NASCIS III, but lack of a placebo-control and similar complication rates diminished further interest in this agent [65]. The endogenous thyrotropinreleasing hormone (TRH) is involved in the hypothalamicpituitary axis, but animal studies revealed that it is also present in synaptic terminals in the spinal cord, and it facilitates motoneuron and sensory neuron excitability and improved function after SCI [66]. A small RCT showed significant improvements in motor and sensory scores at 4 months but had difficulties with a high dropout rate [67]. Further human study of this compound has yet to be reported.

\section{Regenerative Approaches}

Regenerative approaches focus on inducing or amplifying repair mechanisms rather than halting secondary injury. The optimal timing of these interventions remains to be determined - certain repair strategies may have greatest efficacy immediately after injury, whereas others are better suited to the chronic phase after secondary injury has abated. The latter is the rational choice for interventions with substantial risk (e.g., surgical procedures) to avoid subjecting the fraction of patients that have good recovery without intervention to unnecessary risk. 


\section{Cethrin}

The Rho signaling pathway regulates the cytoskeleton and motility and ultimately inhibits neuronal growth [68]. Inactivation of Rho or its downstream target Rho-associated kinase (ROK) stimulates neurite growth, profoundly improving motor function in animal models of SCI [68]. Cethrin is a paste formulation of BA-210, a bacterial-derived Rho-inhibitor, which can be applied directly onto the dura mater intraoperatively. Initial results of a phase I/IIa study in 48 cervical and thoracic SCI patients that used escalating doses demonstrated virtually no motor improvement in thoracic cases, but cervical patients improved $18.6( \pm 19.3)$ points in ASIA motor score, showing a trend toward better recovery than the 10 points expected from historic controls [36•]. Further analysis of the data demonstrated a trend toward sensory improvement in thoracic patients [69]. A large multi-center phase III clinical trial will begin shortly [37].

\section{NSAIDs}

The commonly used non-steroidal anti-inflammatory drugs (NSAIDs), such as ibuprofen, also have inhibitory properties on the Rho pathway, prompting animal studies that demonstrated increased axonal sprouting [70]. A phase I trial is currently investigating an ibuprofen regimen of $2400 \mathrm{mg} /$ day over 4 weeks, with pantoprazole $40 \mathrm{mg}$ /day for gastric protection [38].

\section{Anti-Nogo-A Antibodies}

Similar to the Rho pathway, the myelin protein Nogo-A is a potent inhibitor of neurite growth. A biological strategy to engineer monoclonal antibodies that are selective for NogoA has been shown to enhance the regeneration and reorganization of the injured spinal cord with intrathecal injection in rats and primates [71, 72]. A phase I trial of an anti-Nogo-A antibody (ATI355) administered through an intrathecal pump has been completed, having recruited 51 patients over 5 years with results pending publication [39].

\section{Chondroitinase $A B C$}

An alternative approach to regeneration targets the glial scar that forms at the injury site [73]. The glial scar forms as reactive astrocytes and microglia produce extracellular matrix proteins over a period of months, and this inhibits neurite outgrowth and blocks penetration of regenerative therapies. The bacterial-derived enzyme chondroitinase $\mathrm{ABC}$ has shown beneficial effects in rodents by degrading sugar chains and chondroitin sulphate proteoglycans within the scar, promoting functional recovery [73]. It also appears that the therapeutic benefits of combination treatment with chondroitinase $\mathrm{ABC}$ and anti-Nogo-A are additive, hinting at the future prospect of multimodal SCI therapies [74]. Researchers are currently working on designing a human formulation of chondroitinase $\mathrm{ABC}$ for the purpose of phase I clinical testing.

\section{Hepatocyte Growth Factor}

Hepatocyte growth factor (HGF) acts as a neurotrophic factor and promotes angiogenesis [75]. This compound has also shown promise in a primate model of cervical SCI, preserving corticospinal tract fibers and promoting improved hand function [75]. An ongoing phase I/II placebo-controlled study will evaluate safety and efficacy of recombinant human HGF (KP100IT) [40].

\section{Stem Cells and Cell-Based Therapies}

The use of autologous cellular transplantation to repopulate and repair the injured spinal cord is a fascinating concept, but in reality, cell transplantation strategies may provide more benefit through indirect environmental modification (i.e., cell signalling) [76]. Transplanted stem cells (from several sources) and Schwann cells secrete key trophic factors and inhibitory signals that enhance neuronal survival, axonal outgrowth, and functional plasticity in various animal models [76]. However, recent technological advances allow cellular reprogramming with synthetic mRNA to produce induced pluripotent stem cells and differentiated neural cell types, which may drastically improve the success of direct repopulation strategies [77].

Over the past decade, several phase I human trials have studied various autologous and allogeneic cell lineages (Table 1) [45, 78-83]. Most of these studies inject the cells intraspinally into the lesion site in the acute phase after injury. Results suggest few adverse events, but these studies were not powered to detect functional improvements, and larger controlled studies are needed. Two phase II trials of cell transplantation in human SCI have been completed. Yoon et al. [84] extracted bone marrow stromal cells (BMSCs) and injected them into the injury site along with granulocyte macrophage-colony stimulating factor (GM-CSF) in acute $(n=17)$, sub-acute $(n=6)$, and chronic $(n=12)$ AIS A patients, with $30 \%$ of acute and subacute patients improving at least one AIS grade (nonsignificant compared with controls). Another phase II study of autologous activated macrophages conversely showed a trend toward worse outcomes in terms of AIS grade conversion at 6 months compared to controls [41]. Other phase II clinical trials that are active or planned include implantation of adult neural stem cells, adipose-derived stem cells, and BMSCs [42-44]. 


\section{Bioengineered Scaffolds and Tissue Grafts}

An additional strategy of spinal cord regeneration involves the implantation of a structural construct that bridges the injury and permits axonal regrowth. These implants may consist of synthetic and/or biological tissues that satisfy the fundamental criteria of biocompatibility, biodegradability, appropriate elasticity, cellular adhesion, and axonal regrowth [85]. Many synthetic designs have been developed, such as open-path multichannel synthetic grafts using hydrogel polymers, but it appears that spanning several centimeters of injury requires the incorporation of bioactive molecules and/or living cells [85]. Another approach involves the surgical implantation of peripheral nerve grafts, which also offers a structural conduit for axonal regrowth and provides neurotrophic factors [86]. Experience in animals suggests that axons have difficulty exiting the graft due to glial scarring, but recent work using chondroitinase appears to have facilitated certain axon subtypes successfully crossing and restoring function [87]. An additional alternative consists of self-assembling peptides that form cylindrical nanofibers in situ under physiological conditions $[88,89]$. These bio-engineered molecules are injectable and can be functionalized by incorporating bioactive agents such as neurotrophic factors [89].

\section{The Future of SCI Management}

The future of SCI therapeutics lies in combinatorial strategies that address each mechanism of secondary injury and the multiple roadblocks to successful regeneration. We should anticipate not only additive effects of various neuroprotective agents, regenerative drugs, cell therapies, and structural scaffolds but also supra-additive results due to the systematic elimination of each rate-limiting step. This approach will add great complexity to the research due to the innumerable combinations and permutations of strategies that are possible, but early results in animal studies are strongly supportive of this methodology [74, 87]. For maximum effect, these therapeutic tools must be studied and employed alongside the latest advances in rehabilitation and chronic SCI treatments, which include breakthroughs such as epidural electrical stimulation and functional electrical stimulation [90, 91].

\section{Conclusions}

Scientific evidence has informed our current best practices in diagnosis and acute management of SCI, providing a foundation for clinical practice. However, the SCI community must be prepared for dramatic changes in the years and decades to come, due to the accelerating pace of therapeutic discovery. Major controversies in this field will hopefully be resolved through well-designed clinical trials, such as the diagnostic value of MRI, the role of MP, and the vast array of emerging treatment approaches such as hypothermia, pharmaceuticals, cellular therapies, and engineered materials. We anticipate a bright future for SCI treatment, in which severely injured individuals will achieve profound recovery through complementary phased strategies spanning the acute, sub-acute, and chronic phases.

\section{Compliance with Ethics Guidelines}

Conflict of Interest Allan R. Martin, Izabela Aleksanderek, and Michael G. Fehlings declare that they have no conflicts of interest.

Human and Animal Rights and Informed Consent This article does not contain any studies with human or animal subjects performed by any of the authors.

\section{References}

Papers of particular interest, published recently, have been highlighted as:

- Of importance

•. Of major importance

1. Rowland JW, Hawryluk GW, Kwon B, Fehlings MG. Current status of acute spinal cord injury pathophysiology and emerging therapies: promise on the horizon. Neurosurg Focus. 2008;25, E2.

2.• American Association of Neurological Surgeons (AANS) and the Congress of Neurological Surgeons (CNS), Section on Disorders of the Spine and Peripheral Nerves. Guidelines for the management of acute cervical spine and spinal cord injuries. 2013. Provides numerous updates to the previous 2002 publication of evidencebased management guidelines. Unfortunately, no recommendations are made regarding timing of surgery, and the guideline for methylprednisolone is changed to "treatment not recommended" in contrast to a Cochrane review that recently demonstrated modest efficacy.

3. Brain Trauma Foundation Website. Guidelines for the management of severe traumatic brain injury. 3rd ed. http://www.braintrauma. org/pdf/protected/Guidelines_Management_2007w_bookmarks. pdf Accessed on December 4, 2014.

4. Bromberg WJ, Collier BC, Diebel LN, et al. Blunt cerebrovascular injury. J Trauma. 2010;68(2):471-7.

5.• Fehlings MG, Vaccaro A, Wilson JR, et al. Early versus delayed decompression for traumatic cervical spinal cord injury: results of the Surgical Timing in Acute Spinal Cord Injury Study (STASCIS). PLoS One. 2012;7, e32037. Provides numerous updates to the previous 2002 publication of evidence-based A prospective nonrandomized study of 313 cervical SCI patients showing that decompressive surgery within the first 24 hours (mean $14.2 \mathrm{~h}$ ) confers a 2.83 times (95\% CI 1.10-7.28) higher chance of a 2grade AIS improvement compared with after $24 \mathrm{~h}$ (mean 48.3 h), with no difference in complication rates (early $24 \%$ vs. late $30 \%, p=0.21$ ).

6. Burns AS, Marino RJ, Flanders AE, Flett H. Clinical diagnosis and prognosis following spinal cord injury. Handb Clin Neurol. 2012;109:47-62.

7. Ryken TC, Hadley MN, Walters BC, et al. Radiographic assessment. Neurosurgery. 2013;72:54-72. 
8. Sixta S, Moore FO, Ditillo MF. Screening for thoracolumbar spinal injuries in blunt trauma: An Eastern Association for the Surgery of Trauma practice management guideline. J Trauma Acute Care Surg. 2012;73(5):S326-32.

9. Tator C, Benzel E. (2000). Contemporary management of spinal cord injury. 2nd ed. Thieme/AANS.

10. Aarabi B, Walters BC, Dhall SS, et al. Subaxial cervical spine injury classification systems. Neurosurgery. 2013;72:170-86.

11. Stroman PW, Wheeler-Kingshott C, Bacon M, et al. The current state-of-the-art of spinal cord imaging: methods. NeuroImage. 2014;84:1070-81. Provides a technical description of five emerging methods of imaging that have the potential to dramatically alter the field by non-invasively characterizing microstructure and functional connectivity of the spinal cord, including diffusion tensor imaging, magnetization transfer, myelin water fraction, magnetic resonance spectroscopy, and functional MRI.

12. Cohen-Adad J, El Mendili MM, Lehéricy S, et al. Demyelination and degeneration in the injured human spinal cord detected with diffusion and magnetization transfer MRI. NeuroImage. 2011;55: 1024-33. A prospective cross-sectional study of 14 chronic cervical SCI patients and 14 age-matched controls, showing significant differences in fractional anisotropy, magnetization transfer ratio, and cord area in otherwise healthy appearing areas of the rostral spinal cord

13. Cadotte DW, Bosma R, Mikulis D, et al. Plasticity of the injured human spinal cord: insights revealed by spinal cord functional MRI. PLoS One. 2012;7, e45560. A prospective cross-sectional cohort study of 18 chronic SCI patients and 20 healthy controls, employing functional MRI of the spinal cord comparing thermal stimulation in normal and abnormal dermatomes to controls, showing differences between incomplete SCI patients and controls $(p=0.025)$ and an inverse relationship between sensory impairment and number of activated voxels in abnormal dermatomes $\left(R^{2}=0.93, p<0.001\right)$.

14. American Association of Neurological Surgeons (AANS). Management of acute spinal cord injuries in an intensive care unit or other monitored setting. Neurosurgery. 2002;50(Suppl 3):S51-7.

15. Levi L, Wolf A, Belzberg H. Hemodynamic parameters in patients with acute cervical cord trauma: description, intervention, and prediction of outcome. Neurosurgery. 1993;33(6):1007-16. discussion 1016-1017.

16. Vale FL, Burns J, Jackson AB, Hadley MN. Combined medical and surgical treatment after acute spinal cord injury: results of a prospective pilot study to assess the merits of aggressive medical resuscitation and blood pressure management. J Neurosurg. 1997;87(2):239-46.

17. ClinicalTrials.gov Website. Mean arterial blood pressure treatment for acute spinal cord injury (MAPS). http://www.clinicaltrial.gov/ ct2/show/NCT02232165. Accessed November 20, 2014.

18. Dvorak MF, Noonan VK, Fallah N, et al. The influence of time from injury to surgery on motor recovery and length of hospital stay in acute traumatic spinal cord injury: an observational Canadian cohort study. J Neurotrauma. 2014. A retrospective observational analysis of 1410 Canadian SCI patients that demonstrates that early decompression ( $<24 \mathrm{~h})$ confers improved motor recovery of 6.3 ASIA motor points in AIS B, C, and D patients, and decreases length of stay in AIS A and B patients.

19. Wilson JR, Singh A, Craven C, et al. Early versus late surgery for traumatic spinal cord injury: the results of a prospective Canadian cohort study. Spinal Cord. 2012;50:840-3. A multi-center prospective Canadian cohort study of 84 patients that decompressive surgery within $24 \mathrm{~h}$ increases the chances of a 2grade AIS improvement $(p=0.01)$ and increased ASIA motor score (after adjustments for pre-operative status and neurological level, $p=0.01$ ).
20. Furlan JC, Noonan V, Cadotte DW, Fehlings MG. Timing of decompressive surgery of spinal cord after traumatic spinal cord injury: an evidence-based examination of pre-clinical and clinical studies. J Neurotrauma. 2011;28:1371-99.

21. ClinicalTrials.gov website. Surgical treatment for spinal cord injury (SCI-POEM). http://www.clinicaltrial.gov/ct2/show/ NCT01674764. Accessed November 20, 2014.

22. Gelb DE, Aarabi B, Dhall SS. Treatment of subaxial cervical spinal injuries. Neurosurgery. 2013;72:187-94.

23. Arnold PM, Brodke DS, Rampersaud YR, et al. Differences between neurosurgeons and orthopedic surgeons in classifying cervical dislocation injuries and making assessment and treatment decisions: a multicenter reliability study. Am J Orthop (Belle Mead NJ). 2009;38:E156-61.

24. Rizzolo SJ, Vaccaro AR, Cotler JM. Cervical spine trauma. Spine. 1994;19:2288-98.

25. Jones WHS. Hippocrates. 472nd ed. London: Heinemann; 1923.

26. Levi AD, Casella G, Green BA, et al. Clinical outcomes using modest intravascular hypothermia after acute cervical spinal cord injury. Neurosurgery. 2010;66:670-7.

27.• Bracken MB. Steroids for acute spinal cord injury. Cochrane Database Syst Rev. 2012;1, CD001046. Pooled results of 6 RCTs show no overall neurological benefit of methylprednisolone, but subgroup analysis demonstrated a 4-point improvement on ASIA motor score with 24-h MP administration initiated within $8 \mathrm{~h}$. The data also showed doubling of wound infection and gastrointestinal bleeding rates, but a converse trend toward decreased mortality.

28. Grossman RG, Fehlings MG, Frankowski RF, et al. A prospective, multicenter, phase I matched-comparison group trial of safety, pharmacokinetics, and preliminary efficacy of riluzole in patients with traumatic spinal cord injury. J Neurotrauma. 2014;31:239-55. A prospective cohort study of oral Riluzole in 36 patients with acute SCI showing the cervical subgroup $(n=28)$ improved 15.5 points more than a matched registry control group ( $p=$ $0.02)$, but no benefit in thoracic SCI $(n=8)$. Riluzole showed similar rates of medical complications, although mild-moderate increases in various hepatic enzymes and bilirubin were seen in $\mathbf{1 4}-\mathbf{7 0} \%$ of patients.

29. ClinicalTrials.gov website. Riluzole in Spinal Cord Injury (RISCIS) trial. http://clinicaltrials.gov/show/NCT01597518. Accessed November 20, 2014.

30. Casha S, Zygun D, McGowan MD, et al. Results of a phase II placebo-controlled randomized trial of minocycline in acute spinal cord injury. Brain. 2012;135:1224-36. A single-center placebocontrolled RCT in 44 SCI patients, showing a weak trend toward improvement on ASIA motor scores (6 points, $n=44, p=$ 0.20), but the cervical subgroup showed improvement approaching significance (14 points, $n=25, p=0.05$ ). One event of transient hepatic enzyme elevation was observed.

31. ClinicalTrials.gov website. Minocycline in acute spinal cord injury (MASC). http://www.clinicaltrial.gov/ct2/show/NCT01828203. Accessed November 21, 2014.

32. Takahashi H, Yamazaki M, Okawa A, et al. Neuroprotective therapy using granulocyte colony-stimulating factor for acute spinal cord injury: a phase I/IIa clinical trial. Eur Spine J. 2012;21:2580-7. A phase I/IIa trial of intravenous injection in $\mathbf{1 6}$ humans demonstrated safety, and all 16 patients showed improvement in AIS grade.

33. Inada T, Takahashi $\mathrm{H}$, Yamazaki M, et al. Multicenter prospective nonrandomized controlled clinical trial to prove neurotherapeutic effects of granulocyte colony-stimulating factor for acute spinal cord injury: analysis of follow-up cases after at least 1 year. Spine. 2014;39:213-9. A multi-center non-randomized controlled study (controls at a different institution than G-CSF subjects), 
with 15 of 17 subjects receiving G-CSF improving at least one AIS grade.

34. ClinicalTrials.gov website. Study to evaluate the efficacy, safety, and pharmacokinetics of SUN13837 injection in adult subjects with acute spinal cord injury (ASCI). http://www.clinicaltrial.gov/ct2/ show/NCT02260713. Accessed November 21, 2014.

35. ClinicalTrials.gov website. A phase 2 double-blind, randomized, placebo-controlled study to determine the safety, tolerability and potential activity of $\mathrm{AC} 105$ following a regimen of 6 doses over 30 hours in patients with acute traumatic spinal cord injury $(\mathrm{SCI})$ as compared to patients treated with placebo. http://clinicaltrials.gov/ ct2/show/NCT01750684. Accessed November 20, 2014.

36. Fehlings MG, Theodore N, Harrop J, et al. A phase I/IIa clinical trial of a recombinant Rho protein antagonist in acute spinal cord injury. J Neurotrauma. 2011;28:787-96. A phase I/IIa study in 48 cervical and thoracic SCI patients that used escalating doses demonstrated no motor improvement in thoracic cases, but cervical patients $(n=16)$ improved $18.6( \pm 19.3)$ points in ASIA motor score, showing a trend toward better recovery than the $\mathbf{1 0}$ points expected from historic controls.

37. ClinicalTrials.gov website. Cethrin in Acute Cervical Spinal Cord Injury (CACSCI) trial. http://clinicaltrials.gov/ct2/show/ NCT02053883. Accessed November 20, 2014.

38. ClinicalTrials.gov website. The rho-inhibitor ibuprofen for the treatment of acute spinal cord injury: investigation of safety, feasibility and pharmacokinetics. http://www.clinicaltrial.gov/ct2/show/ NCT02096913. Accessed November 20, 2014

39. ClinicalTrials.gov website. Acute safety, tolerability, feasibility and pharmacokinetics of intrath. administered ATI355 in patients with acute SCI. http://clinicaltrials.gov/show/NCT00406016. Accessed November 21, 2014.

40. ClinicalTrials.gov website. A phase I/II study to evaluate the safety and efficacy of intrathecal injection of KP-100IT in subjects with acute spinal cord injury. http://www.clinicaltrial.gov/ct2/show/ NCT02193334. Accessed November 20, 2014.

41. Lammertse DP, Jones LA, Charlifue SB, et al. Autologous incubated macrophage therapy in acute, complete spinal cord injury: results of the phase 2 randomized controlled multicenter trial. Spinal Cord. 2012;50:661-71.

42. ClinicalTrials.gov website. Autologous bone marrow cell transplantation in persons with acute spinal cord injury - an Indian pilot study. http://www.clinicaltrial.gov/ct2/show/NCT02260713. Accessed November 21, 2014.

43. ClinicalTrials.gov website. Study of human central nervous system (CNS) stem cell transplantation in cervical spinal cord injury. http:// clinicaltrials.gov/ct2/show/NCT02163876. Accessed November 21, 2014.

44. ClinicalTrials.gov website. Transplantation of autologous adipose derived stem cells (ADSCs) in spinal cord injury treatment. http:// www.clinicaltrial.gov/ct2/show/NCT02034669. Accessed November 20, 2014

45. Saberi H, Moshayedi P, Aghayan HR, et al. Treatment of chronic thoracic spinal cord injury patients with autologous Schwann cell transplantation: an interim report on safety considerations and possible outcomes. Neurosci Lett. 2008;443:46-50.

46. Kwon BK, Mann C, Sohn HM, et al. Hypothermia for spinal cord injury. Spine J. 2008;8:859-74.

47. Lo TP, Cho K-S, Garg MS, et al. Systemic hypothermia improves histological and functional outcome after cervical spinal cord contusion in rats. J Comp Neurol. 2009;514:433-48.

48. Dietrich WD, Levi AD, Wang M, Green BA. Hypothermic treatment for acute spinal cord injury. Neurotherapeutics. 2011;8:22939. A case-control study of 14 AIS A patients undergoing induced moderate hypothermia (33C) via intravascular cooling compared with matched controls, showing no difference in complication rates and $6 / 14(43 \%)$ hypothermia subjects converting to incomplete injury compared with $3 / 14(21 \%)$ controls (nonsignificant).

49. ClinicalTrials.gov website. Efficacy of intravenously instituted hypothermia treatment in improving functional outcomes in patients following acute spinal cord injury. http://www.clinicaltrial.gov/ct2/ show/NCT01739010. Accessed November 20, 2014.

50. Fehlings MG, Wilson JR, Cho N. Methylprednisolone for the treatment of acute spinal cord injury: counterpoint. Neurosurgery. 2014;61:36-42.

51. Schwartz G, Fehlings MG. Evaluation of the neuroprotective effects of sodium channel blockers after spinal cord injury: improved behavioral and neuroanatomical recovery with riluzole. J Neurosurg. 2001;94:245-56.

52. Bensimon G, Lacomblez L, Meininger V, the ALS/Riluzole Study Group. A controlled trial of riluzole in amyotrophic lateral sclerosis. N Engl J Med. 1994;330:585-91.

53. Festoff BW, Ameenuddin S, Arnold PM, et al. Minocycline neuroprotects, reduces microgliosis, and inhibits caspase protease expression early after spinal cord injury. J Neurochem. 2006;97: 1314-26.

54. Wells JEA, Hurlbert RJ, Fehlings MG, Yong VW. Neuroprotection by minocycline facilitates significant recovery from spinal cord injury in mice. Brain. 2003;126:1628-37.

55. Kawabe J, Koda M, Hashimoto M, et al. Granulocyte colonystimulating factor (G-CSF) exerts neuroprotective effects via promoting angiogenesis after spinal cord injury in rats. J Neurosurg Spine. 2011;15:414-21.

56. Goldschmidt Y, Sztal TE, Jusuf PR, Hall TE, Nguyen-Chi M, Currie PD. Fgf-dependent glial cell bridges facilitate spinal cord regeneration in zebrafish. J Neurosci. 2012;32(22):7477-92.

57. Rabchevsky AG, Fugaccia I, Turner AF, et al. Basic fibroblast growth factor (bFGF) enhances functional recovery following severe spinal cord injury to the rat. Exp Neurol. 2000;164:280-91.

58. Geisler FH, Coleman WP, Grieco G, Poonian D, The Sygen Study Group. The Sygen multicenter acute spinal cord injury study. Spine. 2001;26(24S):S87-98.

59. Kwon BK, Tetzlaff W, Grauer JN, Beiner J, Vaccaro AR. Pathophysiology and pharmacologic treatment of acute spinal cord injury. Spine J. 2004;4:451-64.

60. Kwon BK, Roy J, Lee JH, et al. Magnesium chloride in a polyethylene glycol formulation as a neuroprotective therapy for acute spinal cord injury: preclinical refinement and optimization. J Neurotrauma. 2009;26:1379-93.

61. Luo J, Borgens R, Shi R. Polyethylene glycol immediately repairs neuronal membranes and inhibits free radical production after acute spinal cord injury. J Neurochem. 2002;83:471-80.

62. Mofidi A, Bader A, Pavlica S. The use of erythropoietin and its derivatives to treat spinal cord injury. Mini Rev Med Chem. 2011;11:763-70.

63. Nikolina E, Tidwell JL, Dai HN. The phosphodiesterase inhibitor rolipram delivered after a spinal cord lesion promotes axonal regeneration and functional recovery. PNAS. 2004;101(23):8786-90.

64. Bracken MB, Shepard MJ, Collins Jr WF, et al. Methylprednisolone or naloxone treatment after acute spinal cord injury: 1-year followup data. Results of the second National Acute Spinal Cord Injury Study. J Neurosurg. 1992;76:23-31.

65. Bracken MB, Shepard MJ, Holford TR, et al. Methylprednisolone or tirilazad mesylate administration after acute spinal cord injury: 1year follow up. Results of the Third National Acute Spinal Cord Injury Randomized Controlled Trial. J Neurosurg. 1998;89:699_ 706.

66. White SR, Crane GK, Jackson DA. Thyrotropin-releasing hormone (TRH) effects on spinal cord neuronal excitability. Ann N Y Acad Sci. 1989;553:337-50. 
67. Pitts LH, Ross A, Chase GA, Faden AI. Treatment with thyrotropin-releasing hormone (TRH) in patients with traumatic spinal cord injuries. J Neurotrauma. 1995;12:235-43.

68. Dergham P, Ellezam B, Essagian C, et al. Rho signaling pathway targeted to promote spinal cord repair. J Neurosci. 2002;22:6570-7.

69. McKerracher L, Anderson KD. Analysis of recruitment and outcomes in the phase $\mathrm{I} / \mathrm{II}$ a cethrin clinical trial for acute spinal cord injury. J Neurotrauma. 2013;30:1795-804.

70. Wang X, Buddel S, Baughman K, et al. Ibuprofen enhances recovery from spinal cord injury by limiting tissue loss and stimulating axonal growth. J Neurotrauma. 2009;26:81-95.

71. Liebscher T, Schnell L, Schnell D, et al. Nogo-A antibody improves regeneration and locomotion of spinal cord-injured rats. Ann Neurol. 2005;58:706-19.

72. Freund P, Schmidlin E, Wannier T, et al. Nogo-A-specific antibody treatment enhances sprouting and functional recovery after cervical lesion in adult primates. Nat Med. 2006;12:790-2.

73. Bradbury EJ, Moon LD, Popat RJ, et al. Chondroitinase ABC promotes functional recovery after spinal cord injury. Nature. 2002;416:636-40.

74. Zhao RR, Andrews MR, Wang D, et al. Combination treatment with anti-Nogo-A and chondroitinase $\mathrm{ABC}$ is more effective than single treatments at enhancing functional recovery after spinal cord injury. Eur J Neurosci. 2013;38:2946-61.

75. Kitamura K, Fujiyoshi K, Yamane J, et al. Human hepatocyte growth factor promotes functional recovery in primates after spinal cord injury. PLoS One. 2011;6, e27706.

76. Ruff CA, Wilcox JT, Fehlings MG. Cell-based transplantation strategies to promote plasticity following spinal cord injury. Exp Neurol. 2012;235:78-90.

77. Warren L, Manos PD, Ahfeldt T, et al. Highly efficient reprogramming to pluripotency and directed differentiation of human cells with synthetic modified mRNA. Cell Stem Cell. 2010;7: $1-13$.

78. Geffner LF, Santacruz P, Izurieta M, et al. Administration of autologous bone marrow stem cells into spinal cord injury patients via multiple routes is safe and improves their quality of life: comprehensive case studies. Cell Transplant. 2008;17:1277-93.

79. Syková E, Homola A, Mazanec R, et al. Autologous bone marrow transplantation in patients with subacute and chronic spinal cord injury. Cell Transplant. 2006;15:675-87.

80. Deda H, Inci MC, Kurekci AE, et al. Treatment of chronic spinal cord injured patients with autologous bone marrow-derived hematopoietic stem cell transplantation: 1-year follow-up. Cytotherapy. 2008;10:565-74.

81. Mackay-Sim A, Feron F, Cochrane J, et al. Autologous olfactory ensheathing cell transplantation in human paraplegia: a 3-year clinical trial. Brain. 2008;131:2376-86.

82. Lima C, Escada P, Pratas-Vital J, et al. Olfactory mucosal autografts and rehabilitation for chronic traumatic spinal cord injury. Neurorehabil Neural Repair. 2010;24:10-22.

83. Knoller N, Auerbach G, Fulga V, et al. Clinical experience using incubated autologous macrophages as a treatment for complete spinal cord injury: phase I study results. J Neurosurg Spine. 2005;3: 173-81.

84. Yoon SH, Shim YS, Park YH, et al. Complete spinal cord injury treatment using autologous bone marrow cell transplantation and bone marrow stimulation with granulocyte macrophage-colony stimulating factor: phase I/II clinical trial. Stem Cells. 2007;25: 2066-73.

85. Wang M, Zhai P, Chen X, et al. Bioengineered scaffolds for spinal cord repair. Tissue Eng B Rev. 2011;17:177-94.

86. Cote MP, Amin AA, Tom VJ, Houle JD. Peripheral nerve grafts support regeneration after spinal cord injury. Neurotherapeutics. 2011;8:294-303.

87. Lee YS, Lin CY, Jiang HH, et al. Nerve regeneration restores supraspinal control of bladder function after complete spinal cord injury. J Neurosci. 2013;33:10591-606.

88. Tysseling-Mattiace VM, Sahni V, Niece KL, et al. Selfassembling nanofibers inhibit glial scar formation and promote axon elongation after spinal cord injury. J Neurosci. 2008;28:3814-23.

89. Liu Y, Ye H, Satkunendrarajah K, et al. A self-assembling peptide reduces glial scarring, attenuates post-traumatic inflammation and promotes neurological recovery following spinal cord injury. Acta Biomater. 2013;9:8075-88.

90. Harkema S, Gerasimenko Y, Hodes J, et al. Effect of epidural stimulation of the lumbosacral spinal cord on voluntary movement, standing, and assisted stepping after motor complete paraplegia: a case study. Lancet. 2011;377:1938-47.

91. Popovic MR, Kapadia N, Zivanovic V, et al. Functional electrical stimulation therapy of voluntary grasping versus only conventional rehabilitation for patients with subacute incomplete tetraplegia: a randomized clinical trial. Neurorehabil Neural Repair. 2011;25: 433-42. 